\title{
Reflexiones acerca de los segmentos medios en la sociedad colonial temprana de Córdoba del Tucumán (1573-1620) ${ }^{1}$
}

\author{
Beatriz Bixio ${ }^{2}$, Constanza González Navarro ${ }^{3}$
}

Recibido: 20 de septiembre de 2017 / Aceptado: 28 de noviembre de 2018

Resumen. A partir del abordaje del proceso de configuración de la sociedad colonial temprana de la ciudad de Córdoba (perteneciente a la gobernación del Tucumán, Virreinato del Perú) entre 1573 y hasta 1620 , el presente trabajo se centra en reflexionar acerca del conjunto de pobladores que no formaron parte de la élite de poder local (constituida por los vecinos beneméritos) ni tampoco integraron los segmentos inferiores o subalternos (indios de encomienda, esclavos, españoles y mestizos pobres). Se trata de un conjunto amplio y heterogéneo de personas que ha sido hasta el momento poco estudiado para América, algunos de cuyos rasgos distintivos se propone discutir y analizar, teniendo en cuenta que manifiesta un creciente peso demográfico a lo largo del período colonial y un rol destacado en la consolidación de las ciudades coloniales. Las fuentes analizadas son diversas y fragmentarias, entre las que podemos mencionar escrituras públicas protocolizadas, actas capitulares y expedientes judiciales de los siglos XVI y XVII.

Palabras clave: Segmentos medios; sociedad colonial; diferenciación social; Córdoba; Gobernación de Tucumán; siglos XVI-XVII.

\section{[en] Thoughts on the Middle Segments of Early Colonial Society in Cordoba del Tucuman (1573-1620)}
Abstract. This article reflects on the group of settlers that did not belong to either the powerful local elites (consisting of distinguished heads of households), nor the lower or subaltern social segments (Indians of the encomienda, slaves, and poor Spaniards or mestizos) in Cordoba (belonging to the Government of Tucuman, Viceroyalty of Peru) between 1573 and 1620, through the study of the configuration of the early colonial society of the city. This large and heterogeneous group of persons has hardly been studied to date. A discussion and analysis of some of the group's distinctive traits is proposed, taking into account its growing demographic importance throughout the colonial period and its outstanding role in the consolidation of colonial cities. The sources analyzed are diverse and fragmented, including notarized public deeds, city council minutes and judicial records of the 16th and 17 th centuries.
Keywords: Middle segments; Colonial society; Social differentiation; Córdoba; Government of Tucumán; 16-17th Centuries.
1 Este trabajo se enmarca en el proyecto de investigación "Proceso de configuración social en Córdoba colonial: un abordaje desde los segmentos intermedios (siglos XVI y XVII)”. PIP. Conicet. N ${ }^{\mathrm{N}}$ 112-201201-00123. Directora: Dra. Beatriz Bixio. 2013-2017.
2 Instituto de Humanidades (IDH). UE CONICET- UNC. Universidad Nacional de Córdoba (Argentina).
E-mail: constanzagn70@yahoo.com.ar
3 Instituto de Estudios Históricos (IEH). UE CONICET-CEH Carlos S.A. Segreti. Universidad Nacional de Cór- doba (Argentina).
E-mail:b.bixio@gmail.com 
Sumario. 1. Fundamentos y propósitos de este trabajo. 2. Ritmo del poblamiento de la ciudad y configuración de los segmentos medios. 3. Libertad, vulnerabilidad y coerción social. 4. Consideraciones finales. 5. Referencias bibliográficas.

Cómo citar: Bixio, B.; González Navarro, C. (2019) Reflexiones acerca de los segmentos medios en la sociedad colonial temprana de Córdoba del Tucumán. (1573-1620), en Revista Complutense de Historia de América 45, 135-158.

\section{Fundamentos y propósitos de este trabajo}

Es un hecho reconocido en la historiografía, las dificultades que devienen de intentar un análisis de las sociedades coloniales a partir de criterios tales como el estamental, étnico o socioeconómico, "incapaces de reflejar la complejidad social de la América Colonial"'. La versatilidad y dinamismo es lo que caracteriza a la sociedad americana. En efecto, siguiendo a Serrera ${ }^{5}$, sostenemos que si bien ésta abreva en los criterios de diferenciación social peninsulares (claramente estamentales) no puede ser asimilada directamente a ella en la medida de que la experiencia no se corresponde con los patrones sociales de los horizontes geográficos y culturales que le dieron origen. Se trata en todo caso de una sociedad caracterizada por "jerarquías múltiples", en la que se activaron criterios originales de rango social ${ }^{6}$.

En esta oportunidad intentaremos una primera aproximación a la franja intermedia de la sociedad de Córdoba del Tucumán en las décadas inmediatamente posteriores a su asentamiento, concretamente, entre 1573 -fecha de fundación de la ciudady 1620, abordando el conjunto de sujetos que no es pasible de ser incluido ni en la élite (vecinos feudatarios, funcionarios de alto rango y grandes comerciantes) ni en los sectores subalternos (indios, esclavos, españoles y mestizos pobres). Se trata de reconocer el peso específico de este sector, identificando el proceso mediante el cual adquirió presencia numérica y social en la ciudad.

La sociedad tucumana más temprana -pero que en el contexto de la historia americana correspondió a la ocupación y poblamiento tardíos- estaba segmentada, en principio, en dos grandes conjuntos: los beneméritos de la conquista -y sus descendientes- $y$ los indios de encomienda, ambos ubicados en los extremos opuestos de la jerarquía social. En el medio de ellos, quedaba una amplia franja, constituida por una cuantiosa población, jerarquizada, variable, móvil, de difícil caracterización social, cuyo número aumentó desde la fundación de la ciudad y a lo largo de todo el siglo XVII, que hasta el momento ha sido escasamente estudiada. Los miembros de esta franja fueron los llamados "hombres libres" en la sociedad peninsular, categoría que incluía a los habitantes de ciudades, villas, pueblos, caseríos y campos que figuraban sin ninguna adjetivación. En ella cabían aquéllos asentados como "naturales" de tal o cual lugar y que también constituían la gente del "común" que, por oposición a la nobleza, en la península ibérica pagaba pechos/impuestos y en América no ${ }^{7}$. Esta gran franja de población peninsular se amplió con otro grupo de población nacida en

\footnotetext{
Ponce Leiva, 2007: 5.

Serrera, 2011.

Ibídem: 138 .

Lobos, 2009: 534.
} 
América (de padres españoles o españoles e indígenas) y que también pasaría a constituir los núcleos poblacionales más tardíamente fundados como los del Tucumán.

Muchos de ellos, a pesar de carecer de títulos nobiliarios, formaron parte de las élites locales y adquirieron el carácter de hidalgos merced a su participación en las expediciones de conquista y población. No obstante ello, una gran parte conformó una franja social intermedia, caracterizada por su heterogeneidad y movilidad, aspectos que han sido obstáculos para su indagación, hasta el punto de que pareciera que sólo pueden abordarse a partir de estudios de caso. El carácter relacional de esta franja puede visibilizarse desde su primera caracterización: se los llama entre-medio social $^{8}$, categorias sociales intermedias ${ }^{9}$, sectores dependientes ${ }^{10}$, grupos medios ${ }^{11}$, lo medio, o sectores medios ${ }^{12}$, nominaciones que no son categorías sociales nativas sino del investigador y por ello se corre el riesgo de extrapolar categorías actuales a la comprensión del pasado. De hecho, en el conjunto de sociocategorías nativas no hay un término que unifique a este sector.

La heterogeneidad de este segmento es señalada por Brígida Von Mentz ${ }^{13}$ para el caso novohispano, sugiriendo la utilización del término burguesía para referirse a un sector social amplio que incluiría a los grupos especialmente urbanos relacionados con el comercio y con la producción artesanal o manufacturera, en general dueños de los medios de producción e interesados en la productividad de sus empresas. Una parte importante de este grupo novohispano se caracterizó por ser propietaria y aspirar al control de instituciones como el cabildo, tratando de hermanar su poder económico con el político. Otra parte de la burguesía novohispana estaba constituida por profesionistas liberales, dedicados al transporte, actividad minera o producción agrícola comercial, contando con bienes urbanos y cierta educación sólo accesible en la urbe. Una diferencia que marca la autora entre la burguesía europea y la americana colonial es que en la segunda jugaron un papel más importante dos factores, el étnico (oposición entre el blanco europeo y el indígena, el mestizo o el africano), así como el origen (oposición entre americanos y europeos). La autora indica, además, que para el caso novohispano el término burguesía abarcaba una amplia gama de grupos sociales que incluía a los segmentos citadinos más bajos (como los maestros artesanos independientes) $)^{14}$. Propone ampliar el término "burguesía" a los sectores medios urbanos desde el siglo XVI en adelante. Sin embargo, se trata de un término difícil de aceptar para el caso de Córdoba en los primeros años de poblamiento en tanto el factor étnico no parece ser definitorio, la mayoría de sus miembros no son propietarios y no aspiran al control del cabildo. De allí que prefiramos conservar la expresión "entre-medio social, segmentos o sectores medios", a fin de destacar su heterogeneidad y advertir sobre la posibilidad de agrupamientos a su interior definidos por solidaridades, objetivos o identidades comunes.

Admitimos que sólo el proceso de investigación permitirá resolver el problema de si los sujetos de este colectivo pueden ser definidos como un grupo social vivido o experimentado. Somos conscientes de que estamos inmersos en "la paradoja que

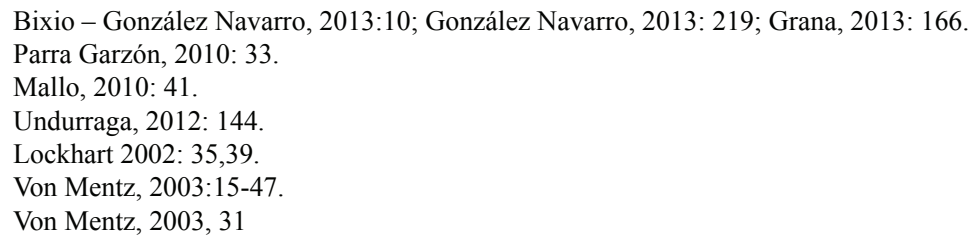


encierra el análisis de lo social", que tiene el riesgo de hacer circular nuestras consideraciones: si para comenzar la investigación tomamos como punto de partida un conjunto de personas a las que consideramos a priori un grupo, el análisis puede consistir sólo en su validación, dados los principios a partir de los cuales este grupo se ha confeccionado. Sólo podremos, por tanto, partir del estudio de los individuos y proponer una modelización que no es sino un modo de comprensión del funcionamiento de lo social ${ }^{15}$.

En coherencia con estas observaciones, orientamos este estudio a la indagación de un conjunto de personas específicas, definidas a partir de ciertos rasgos compartidos. No es el rol lo que los define, pues ellos pertenecen a un conjunto muy heterogéneo de socio-ocupaciones. Todos se caracterizan por su no pertenencia a los extremos de la escala social y por ser portadores de ciertos saberes generalmente no formalizados o un savoir faire particular ${ }^{16}$. Tal como lo ha señalado Yves Deforge el savoir faire se define como la capacidad para cumplir/tener éxito en una actividad particular a través de un empeño personal, lo que es tributario del ambiente social y natural, de las aptitudes psíquicas e intelectuales de los individuos, pero también de una capacidad de reflexión que permite operar sobre los savoir-faire para adaptarlos, modificarlos, transferirlos, combinarlos y reencauzarlos. Esto es, la mayoría de los sujetos que ubicamos específicamente en el entre-medio cuenta con algún saber que les ha servido para procurarse un medio de vida (un saber manual, el conocimiento de la lengua nativa, de la lecto-escritura, saber tratar y contratar vinculado a la compra y venta de productos, saber curar, etc.). O sea, poseen algo más que su fuerza de trabajo para ofrecer en un mercado consumidor en formación: sea productos manufacturados (artesanos), sea bienes de consumo o de uso (tenderos, pequeños comerciantes, pulperos) o servicios (médicos, cirujanos y barberos, administradores, pobleros, fleteros).

Excluimos de esta investigación el análisis de los grandes comerciantes locales y tratantes de larga distancia, que pueden tener prácticas que los asemejan al grupo de los encomenderos, lo que ha sido llamado por Langue ${ }^{17}$ "permanencia del modelo aristocrático", perceptible en grandes comerciantes que conforman una suerte de "elite secundaria", sin consagración nobiliaria pero distinguida a partir de su riqueza. También excluimos de este conjunto a los denominados "pobres" en la documentación, esto es, mestizos, españoles e indios libres que no tienen una profesión, que realizan tareas no calificadas dado que sólo cuentan con su fuerza de trabajo, que se conchaban para diferentes tareas rurales, como peones, o urbanas, como constructores, o acompañan en viajes a los fleteros.

Partimos de la hipótesis de que este segmento responde a patrones de comportamiento, diferenciación y legitimación social variados, que se distinguen de aquéllos que lleva adelante la élite encomendera o los sectores subalternos propiamente dichos.

El período que transcurre entre fines del siglo XVI y primer cuarto del XVII estuvo dominado económicamente por las actividades textiles y la cría de ganado vacuno, estimulado por el polo de atracción del mercado potosino y otros destinos importantes como Brasil. La producción lanar y la cría de animales se obtenía de las

\footnotetext{
Guerra, 2000: 120 .

Deforge, 1996: 199 .

Langue, 1992: 127.
} 
estancias españolas, muchas de las cuales también contaban con obrajes cuyas manufacturas eran elaboradas por la población indígena sometida al régimen de encomiendas ${ }^{18}$. Esta actividad económica, aunque introdujo a Córdoba en un importante mercado regional, y aunque involucró esencialmente a la población indígena -más tarde suplida por la esclava- incluyó una muy pequeña parte de población de los sectores medios, sólo aquélla constituida por españoles y mestizos que cumplían la función de dirigir la producción y enseñar oficios como la tejeduría, carpintería, fabricación de cordobanes, etc. a los nativos ${ }^{19}$. Es entre 1610 y 1615 cuando empieza la curva descendente de la producción textil, condicionada por el descenso de la población nativa que constituía la mano de obra específica de esa actividad, para alcanzar su punto más bajo en $1630^{20}$. La economía se reorienta paulatinamente hacia otras actividades que demandan menos trabajadores como la cría y comercialización del ganado mular cuya demanda aumenta en los centros mineros.

Más allá de estos grandes sectores en los que se desarrolla la economía de Córdoba del período, el funcionamiento de la ciudad, la necesidad de viviendas, obras públicas, abastecimiento, bienes de consumo, así como el progresivo aumento de la capacidad económica del sector de encomenderos y grandes comerciantes y el crecimiento de la población en general, provocan un desarrollo de aquellos sectores capaces de satisfacer las demandas de muebles, viviendas, alimentos, ropa, calzado, objetos de lujo, instrumentos de trabajo, cabalgaduras, etc. De manera que lo que denominamos el entre-medio de la sociedad sufre un engrosamiento paulatino, siendo en principio una población flotante y que con el tiempo elige como lugar de residencia permanente la ciudad de Córdoba.

El desarrollo en las últimas décadas de los estudios históricos focalizados en las élites ha sido relacionado con su sobrerrepresentación en las fuentes, especialmente en fuentes administrativas y diplomáticas, muchas de ellas producidas por estos mismos actores. Por el contrario, los miembros del segmento medio raras veces tienen protagonismo en los documentos y es difícil hallarlos de manera recursiva, de modo que podamos acceder a sus historias de vida. Sin embargo, y aunque lo hagan de manera lateral, aparecen por doquier en la mayoría de los tipos de fuentes, aunque muchas veces sólo como actores secundarios sin un verdadero protagonismo que permita inferir algo más que su existencia, el rol que cumplen, y algún otro dato accesorio. Con pocas excepciones, queda fuera de estos documentos lo relativo a su vida cotidiana, ideales, subjetividad, que debe ser inferida a partir de unos pocos indicios. Así, en las actas de cabildo se los suele encontrar peticionando o, las más de las veces, siendo objeto de control y/o de reglamentación de las actividades que realizan. También aparecen con frecuencia en escrituras públicas protocolizadas (realizando conciertos o contratos de trabajo, testificando, efectuando pequeñas transacciones, etc.) en estructuras formularias que indican nombre, profesión o actividad y algunos pocos datos más. Sólo en el caso de los testamentos la información permite reconstruir algunos aspectos de sus trayectorias de vida. En los juicios civiles y penales su imagen se delinea con más claridad y su protagonismo es mayor. Aquí se los encuentra actuando, solicitando, requiriendo justicia, testificando, etc., lo que habilita el entendimiento de sus posicionamientos sociales e individuales.

\footnotetext{
Piana de Cuestas, 1992; González Navarro, 2009.

González Navarro, 2013.

Assadourián, 1973: 174.
} 


\section{Ritmo del poblamiento de la ciudad y configuración de los segmentos medios}

Los datos poblacionales de esta época son siempre subjetivos, aproximados, responden a ciertos intereses e incluso, muchas veces son inconsistentes entre sí. Más allá de este reconocimiento, se advierte en el período que nos compete un proceso muy claro: a) una relativa estabilidad del número de vecinos encomenderos y beneméritos (que oscila desde comienzos de la fundación de la ciudad hasta 1620 entre 30 y 60) y b) descenso drástico de la población nativa, pues de los 30.000 "indios, gente toda" (esto es hombres y mujeres) que registraba la Relación Anónima ${ }^{21}$ al momento de la fundación de la ciudad de Córdoba (1573), hacia 1607 el gobernador Rivera registraba un número de 4.113 indios encomendados para la jurisdicción ${ }^{22}$. A pesar de lo poco exacto de las cifras, distintos autores han coincidido en calificar el fenómeno de las poblaciones nativas como una "catástrofe demográfica" similar a la que ocurrió en otras regiones de América colonial ${ }^{23}$.

Para 1629 (más de 50 años después de la fundación), el entonces gobernador, don Felipe de Albornoz, destacaba que siendo Córdoba la ciudad más poblada de la gobernación "apenas llega entre vecinos y moradores a doscientas casas y las demás unas con otras ninguna pasa de cincuenta" ${ }^{24}$. Esta última referencia muestra un crecimiento importante de la población local, especialmente de la franja que no había adquirido la condición de vecino y que podemos considerar que englobaba a una buena parte de los segmentos medios. Este aumento de la población en general es acorde con la información que aportan otras fuentes como las que analizan Lobos y Gould indagando sobre el flujo migratorio europeo a la región en el siglo XVII ${ }^{25}$.

Las referencias mencionadas, por su naturaleza, no nos permiten estimar el volumen de población cordobesa que se ubicaba dentro de los segmentos medios. Por esta razón es que consideramos necesario proponer una metodología ad hoc. Para ello hemos realizado un relevamiento y reunido una muestra de un conjunto de sujetos individualizados en muy variados tipos de fuentes ${ }^{26}$-ubicadas cronológicamente entre 1573 y 1620-, seleccionados porque: 1) detentan un savoir faire específico, 2) no se encuentran asociados con las familias de vecinos beneméritos, no detentan cargos en el cabildo ni funciones públicas, 3) no están sujetos a vínculos de dependencia a perpetuidad (como la encomienda o la esclavitud). En general estos criterios son factibles de ser establecidos con facilidad a través de escrituras y contratos protocolizados que hemos consultado.

En el gráfico 1 se presenta la composición ocupacional de la muestra de segmentos medios a partir de 140 casos identificados en un relevamiento de las escrituras públicas asentadas en el Archivo Histórico de la Provincia de Córdoba comprendidas entre 1574 y 1620 . Es importante aclarar que hemos seleccionado aquéllas en las que es posible discernir con claridad esta condición: contratos de trabajo de artesanos y aprendices, la formación de compañías, cartas de obligación, cartas de fianza para apertura de pulperías que dan cuenta de que vivieron y tuvieron asiento en la ciudad

\footnotetext{
21 Berberián, 1987: 227.

22 Carta del gobernador de Tucumán, Alonso de Rivera al Rey. Santiago del Estero, 19-III-1607; ref. en Segreti, 1999: 39.

23 Doucet, 1987.

24 Ibídem: 77.

25 Lobos - Gould, 1998:58-60.

26 Se utilizaron principalmente los registros de protocolos de escribanos y fuentes judiciales de las fechas indicadas.
} 
-y no sólo transitaron- en un momento de sus vidas. Complementariamente, se ha utilizado, además, la información proveniente de un conjunto acotado de expedientes sucesorios y pleitos que involucran a miembros del segmento medio, ya sea como actores de la causa o testigos. El fondo de justicia, permite, en efecto, reconocer el accionar y los conflictos derivados de la interacción de los sujetos analizados. En este mismo fondo, los testamentos e inventarios de bienes contenidos en los juicios sucesorios son útiles para analizar las trayectorias de vida, los lazos sociales, las acreencias y las deudas. Por su parte, los expedientes por tutorías de menores son especialmente ricos en información por los recibos de pago que contienen como parte de las rendiciones de la administración de los bienes. En ellos es posible identificar nombres de comerciantes, artesanos y profesionales que prestaron algún servicio o realizaron alguna transacción, estipulando montos y tipos de servicios, y dando cuenta de sus aptitudes para firmar. A menudo, los nombres que aparecen en el fondo de justicia, se repiten en otros documentos como los registros de protocolo o inclusive en las actas de cabildo -fuente también relevada- donde aparecen peticionando o labrando contratos por servicios ante el cuerpo capitular (véase, por ejemplo, constructores o carpinteros que trabajan para las obras de la ciudad).

Gráfico 1. Distribución socio-ocupacional de los sectores medios (1573-1620 ${ }^{27}$.

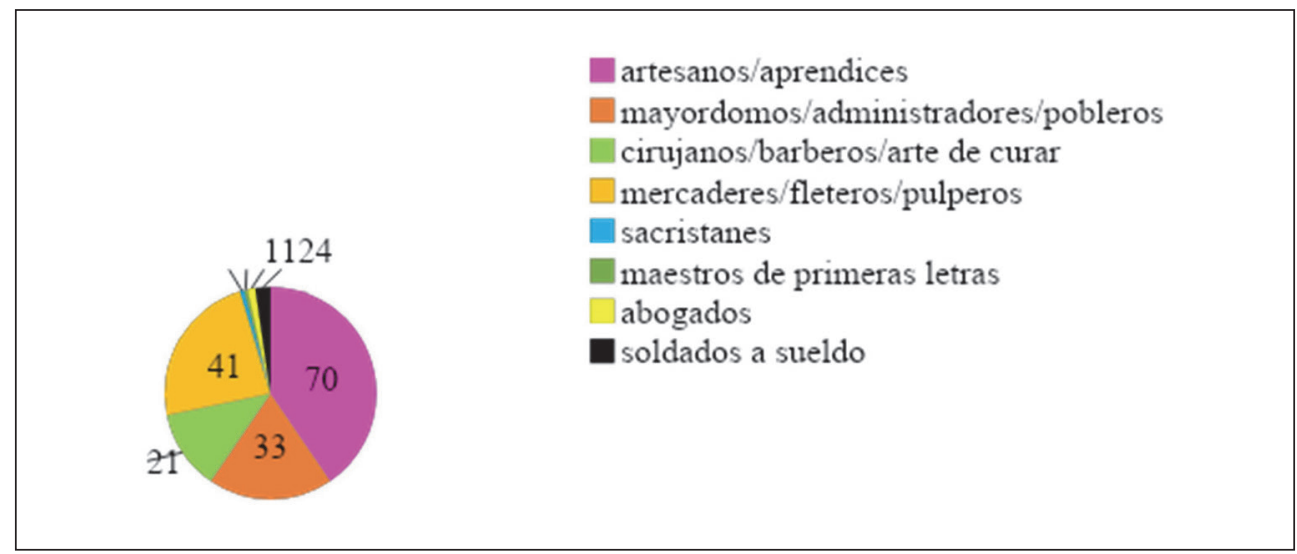

Como se observa, la muestra está compuesta en su mayoría por artesanos en un $40 \%$, le siguen los mercaderes, fleteros y pulperos con un $24 \%$, los mayordomos, administradores y pobleros con un 19\%, los cirujanos, barberos e idóneos en el arte de

27 Fuente: elaboración propia en base al relevamiento realizado de escrituras públicas contenidas en el Archivo Histórico de la Provincia de Córdoba (en adelante AHPC) [Argentina], sección Protocolos, Registro 1, Tomos 1 al 35 comprendidos entre 1574 y 1620. También se utilizó una selección de expedientes judiciales contenidos en la sección Escribanía (en adelante Esc.) 1, leg. 1, exp. 13; leg. 3, exp. 7; leg. 5, exp. 6; leg. 6, exp. 3; leg. 7, exp.1; Leg. 10, exp. 1; leg. 11, exp. 2; leg. 14, exp. 6; leg. 15, exp. 1; leg. 16, exp. 8; leg. 17, exp. 12; leg. 29 , exp.2; leg. 32 , exp. 6; leg. 37, exp. 1; leg. 41, exp. 2. Una fuente muy valiosa que se ha consultado son los expedientes de tutoría de menores, donde los tutores presentan recibos de pago por los gastos y allí se detectan numerosos registros de servicios o bienes adquiridos a manos de miembros de los segmentos medios; por ejemplo: Tutoría de Alonso y Ana de Salvatierra. Córdoba, 1605. AHPC, Esc. 1, leg. 17, exp 12. 
curar con un $12 \%$, y en menor medida los soldados a sueldo $(2 \%)$, sacristanes $(1 \%)$, abogados (1\%) y maestros (1\%).

Durante las primeras décadas de la ciudad de Córdoba no es factible definir con claridad los límites de lo urbano o lo rural, ya que la mayoría de la población realiza actividades tanto dentro como fuera de la traza de la ciudad. No obstante, una gran parte de los segmentos medios van configurando su ámbito de actividades en el interior de la traza. Los soldados a sueldo, en cambio, generalmente prestaban servicios en las expediciones o entradas a la tierra para cumplir con el deber de vecindad de algún vecino menor de edad o que no deseara o pudiera hacerlo por otra razón; los mayordomos, administradores de estancias y encomiendas residían en los establecimientos productivos casi todo el año. Finalmente, el caso de los fleteros merece un análisis aparte por cuanto sus actividades son por naturaleza móviles y no ofrecen una localización absoluta urbana o rural. Por otra parte, para el período que nos ocupa, aún no es posible identificar un número significativo de productores rurales de rango medio. Estos se hacen particularmente presentes luego de 1620 cuando la economía local sufre una reorientación hacia otras producciones (como la mular). De manera tal que, como advierte Lockhart, en el período temprano colonial la mayor parte de los segmentos medios se localizaron en el ejido urbano, lo cual puede considerarse como un patrón general de la organización social latinoamericana: "lo alto y lo medio en las ciudades y lo bajo en el campo" 28 .

El predominio de los sectores medios en la traza de la ciudad y su creciente presencia en el conjunto poblacional cordobés, podría revelar que esta población tuvo un rol protagónico en la consolidación de la ciudad y posiblemente también en la configuración creciente y diferenciada del espacio urbano por oposición al rural. Aunque es imposible brindar valores absolutos de esta población para una fecha dada debido a los movimientos constantes de la población y a la falta de fuentes estadísticas, el gráfico 2, elaborado en base a nuestro propio relevamiento, y dividido en períodos veinteañales muestra una tendencia creciente en el período 1596-1615.

Gráfico 2. Presencia numérica de los segmentos medios en Córdoba cada veinte años ${ }^{29}$.

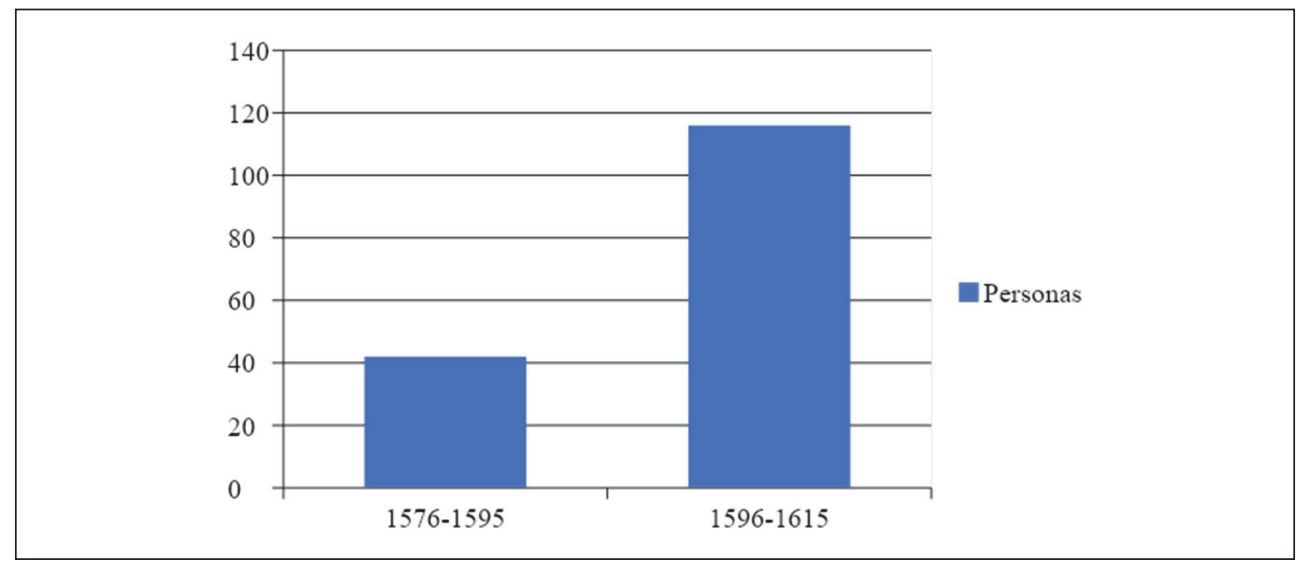

Lockhart, 2002: 35.

29 Fuente: ver nota 27. 
Es este segmento intermedio el que, fundamentalmente, exhibe la multietnicidad de la sociedad colonial. A diferencia de los dos grupos que se encuentran en los extremos, el entremedio de la sociedad es multiétnico en el sentido de que está constituido por peninsulares, portugueses, indígenas y mestizos, todos ellos -o la mayoría- producto de la inmigración y el traslado constante de población. Recién luego de 1630 se incorpora a esta franja social intermedia población de origen africano. A pesar de que en la muestra hay un predominio de europeos por tratarse de personas que tienen más posibilidades de asentar por escrito y/o protocolizar las transacciones y contratos, se observa que todos los grupos étnicos están representados en alguna medida. Los españoles y portugueses peninsulares o nacidos en América son los que en su mayoría cuentan con oficios y habilidades para contratarse. Particularmente relevante es la presencia de portugueses que actúan como mercaderes pero también como artesanos afincados en la ciudad.

Una menor proporción de los segmentos medios está representada por indios forasteros, generalmente del Perú o Chile pero también de otras jurisdicciones (Santiago del Estero, Esteco y Santa Fe principalmente), que ofrecen servicios o pactan contratos para ejercer un oficio o como pobleros/mayordomos. Estos forasteros, a veces declaran estar sujetos a un amo residente en otra ciudad del cual se han desvinculado hace tiempo o a veces ni siquiera lo declaran. Su relación laboral generalmente se pacta con vecinos principales pero también con otros miembros del sector medio que no pueden acceder a la mano de obra indígena local a través del sistema de encomienda. A pesar de que en teoría los indios forasteros dependen de un encomendero, con el tiempo van desvinculándose hasta olvidar por completo los antiguos lazos de dependencia. Así pues, se observa en una causa criminal de 1609, el indio Diego, zapatero (acusado de matar al indio Gerónimo, sillero), declaraba ser natural de Santiago del Estero de la encomienda de Villareal y estar trabajando en Córdoba en la tienda de Álvaro Ramallo. Declaraba haber abandonado su pueblo y llegado a Córdoba hacía 21 años ${ }^{30}$. Los derroteros del indio Diego revelan que las relaciones contractuales de los forasteros -ya desvinculados de sus amos-gozaban de mayor libertad que la que poseían los indios sometidos al sistema de encomienda.

La población de origen africano merece un párrafo aparte. La muestra que hemos podido reunir revela que este segmento está prácticamente ausente, y es que, para el período 1573-1620, Córdoba constituye una activa plaza de compra-venta de escla$\operatorname{vos}^{31}$ pero no un área donde se concentre una gran población estable de ese origen. Los pocos que se encuentran registrados en las fuentes, son esclavos que no poseen libertad para prestar servicios por cuenta propia, aun cuando cuenten con un oficio. Son los amos los que se ocupan de garantizar su entrenamiento para luego obtener algún beneficio suplementario ${ }^{32}$. Son pocos los casos de mulatos o negros libres que ejercen un oficio o actividad lucrativa por cuenta propia y que podríamos encuadrar en el escalón más bajo de los segmentos medios. Se trata de los que cumplen funciones de pobleros, como es el caso de Juan Méndes mulato, que se concierta con Juan de Burgos en 1581 y por el término de 4 años para administrarle su encomienda,

30 Luis de Acevedo como tutor y curador ad liten de los indios de Santiago del Estero y Esteco en la causa criminal de oficio contra los dichos por muerte dada a Gerónimo indio. Córdoba, 1609. AHPC, Esc. 1, leg. 21, exp. 1.

Assadourián, 1965.

32 Es el caso de Juan Justiniano que en 1600 es entregado por su amo al sastre Amador Páez para que le enseñe el oficio. Concierto, 19-IX-1600. AHPC, Registro (en adelante Reg.) 1, tomo 12, f. 197v-198v. 
o Antón López, mulato, mencionado en las actas de cabildo de 1603 ejerciendo el mismo tipo de trabajo ${ }^{33}$.

El nivel de riqueza de este segmento es variable y difícil de establecer. Entre fines del siglo XVI y primera mitad del siglo XVII la muerte de un miembro de los segmentos medios algunas veces - pero no siempre- provocaba la realización de un inventario y una venta en almoneda de algunos de sus bienes para saldar las deudas, pero rara vez incluye la tasación completa de todo su patrimonio. De manera que la información con la que contamos siempre es indirecta y fragmentaria. Los registros revelan que su capital económico acumulado a lo largo de la vida era generalmente inferior al de la élite. Para el período 1600-1650 la mayoría de los miembros de la élite propietaria de Córdoba tenían capitales (en bienes muebles, inmuebles y semovientes) que oscilaban entre los 2000 y los 23.000 pesos $^{34}$. Los segmentos medios se ubican por debajo de este valor, como es el caso del portugués Simón Duarte, mayordomo, comerciante y pulpero, quien expresa que a la muerte de su mujer, ocurrida cinco meses antes de su testamento, contaba con un caudal de aproximadamente cuatrocientos pesos. Gonzalo indio, poblero, al morir en 1584 sumaba un total de 486 pesos y medio en bienes ${ }^{35}$. En este caso, como en otros que podemos reconocer, las personas no cuentan con bienes en moneda para el pago siquiera del testamento, entierro o de las mandas forzosas y deben solicitar que se los entierre de limosna o que se vendan en almoneda sus bienes para ello.

Los ingresos que percibían a través de sus actividades económicas variaba. Los recibos de pago como las cartas de concierto por servicios son una muestra de lo que se podía cobrar por ciertos trabajos según su nivel de especialización y el tiempo demandado. Tal como puede observarse en los cuadros 1 y 2 , el ejercicio de ciertos oficios/profesiones/saberes implicaba contratos por períodos de tiempo acordados que podían ser de carácter exclusivo o no, mientras que en otros casos se pactaba por tarea cumplida u obra realizada, cuyo tiempo de ejecución no quedaba asentado sino que dependía del cumplimiento de la tarea convenida por el prestador.

Tabla 1. Contratación de servicios por tiempo ${ }^{36}$.

\begin{tabular}{|l|l|c|l|}
\hline \multicolumn{1}{|c|}{ Nombre } & \multicolumn{1}{|c|}{ Servicios por límite de tiempo } & Año & \multicolumn{2}{|c|}{ Paga } \\
\hline Juan Mendez, mulato & Poblero por dos años ${ }^{37}$ & 1581 & $\begin{array}{l}\text { El quinto de toda la } \\
\text { producción }\end{array}$ \\
\hline Andres de Contreras & $\begin{array}{l}\text { Servicio de cuidado de hacienda y } \\
\text { cumplimiento de vecindad por un año }\end{array}$ & 1585 & $\begin{array}{l}100 \text { pesos. Armas, caballo, } \\
\text { casa y comida. }\end{array}$ \\
\hline Miguel de Rute & Servicio de poblero por un año & 1594 & $\begin{array}{l}90 \text { pesos en moneda de la } \\
\text { tierra }\end{array}$ \\
\hline Licenciado Ojeda & $\begin{array}{l}\text { Patrocinio de pleitos de un vecino por } \\
\text { el año } 1597\end{array}$ & 1597 & $\begin{array}{l}80 \text { pesos pagados en ropa de } \\
\text { la tierra. }\end{array}$ \\
\hline
\end{tabular}

\footnotetext{
Actas Capitulares (en adelante AC), 12-VII-1603. Santillán Vélez, 1883, libro 4: 21-27.

González Navarro - Marschoff, 2016.

Sucesión de Gonzalo indio. Córdoba, 1587-1589. AHPC, Esc.1, leg. 2, exp. 10.

Fuente: elaboración de las autoras en base a escrituras varias del AHPC.

Concierto. Córdoba, 7-IV-1581. AHPC, Reg. 1, t. 2, f. 78r.
} 


\begin{tabular}{|l|l|c|l|}
\hline \multicolumn{1}{|c|}{ Nombre } & \multicolumn{1}{|c|}{ Servicios por límite de tiempo } & Año & \multicolumn{1}{|c|}{ Paga } \\
\hline Melchor de Acuña & $\begin{array}{l}\text { Poblero en encomienda de Guamacha } \\
\text { por un año }\end{array}$ & 1598 & 150 pesos \\
\hline Joan Baptista de Mena & $\begin{array}{l}\text { Enseñanza de primeras letras a un } \\
\text { niño por 11 meses }\end{array}$ & 1604 & 50 pesos \\
\hline Francisco Bernardo Jijón & $\begin{array}{l}\text { Atender a los enfermos del hospital } \\
\text { por un año }\end{array}$ & 1606 & $\begin{array}{l}50 \text { pesos e indios de servicio } \\
\text { del hospital }\end{array}$ \\
\hline Francisco Falcon & $\begin{array}{l}\text { Tareas de carpintería y en lo que } \\
\text { mandare por un año }\end{array}$ & 1618 & 250 pesos y de comer \\
\hline
\end{tabular}

Tabla. 2. Contratación de servicios por obra terminada ${ }^{41}$.

\begin{tabular}{|c|c|c|c|}
\hline Nombre & Servicio & Año & Retribución \\
\hline Pedro de la Torre & $\begin{array}{l}\text { Construcción de una casa a terminar } \\
\text { en } 5 \text { meses }^{42}\end{array}$ & 1587 & 125 pesos en telas y cosas. \\
\hline Mateo de Sorya Sarmiento & $\begin{array}{l}\text { Venta de } 1 \text { vara y dos tercias de paño } \\
\text { de Quito para un vestido }{ }^{43}\end{array}$ & 1597 & 16 pesos \\
\hline Pantaleón Rodríguez & Hechura de un vestido ${ }^{44}$ & 1598 & 8 pesos \\
\hline Jorge Lozada & Hechura de una saya ${ }^{45}$ & 1598 & 6 pesos \\
\hline Álvaro González & Hechura de dos cerrojos para puerta ${ }^{46}$ & 1598 & 13 pesos \\
\hline Diego González Herrero & Hechura de herramientas del molino $0^{47}$ & 1598 & 72 pesos y 2 reales \\
\hline Pantaleón Rodríguez & $\begin{array}{l}\text { Elaboración de } 18 \text { herraduras con sus } \\
\text { clavos }^{48}\end{array}$ & 1599 & 18 pesos \\
\hline Juan de Arana & $\begin{array}{l}\text { Sacristán, "limosna" por servicio de } \\
\text { un entierro de un yanacona }{ }^{9}\end{array}$ & 1600 & 3 pesos \\
\hline Reginaldo Juan ${ }^{50}$ & Terminación de casas del cabildo & 1610 & $\begin{array}{l}115 \text { pesos en reales, tablas, } \\
\text { clavos e indios de servicio }\end{array}$ \\
\hline $\begin{array}{l}\text { Gonzalo Carualho (maestro } \\
\text { de carpintería) }\end{array}$ & Construcción de la iglesia Catedral & 1620 & $\begin{array}{l}900 \text { pesos pagados conforme } \\
\text { avance la obra. }\end{array}$ \\
\hline
\end{tabular}

38 Sucesión de Blas de Peralta. Córdoba, 1600. AHPC, Esc. 1, leg. 10, exp. 1, f. 101 r.

39 AC, 14-VII-1606. Santillán Vélez, 1883, libro 4: 235-236.

40 Concierto. Córdoba, 13-VII-1618. AHPC, Reg. 1, t. 32, f. 94v-95r.

${ }_{41}$ Fuente: elaboración de las autoras en base a escrituras varias del AHPC.

42 Concierto. Córdoba, 3-IV-1587. AHPC, Reg. 1, t. 3, f. 202v.

43 Sucesión de Martín de Salvatierra, Córdoba, 1605. AHPC, Esc. 1, leg. 17, exp. 12.

44 Ibídem.

45 Ibídem.

46 Ibídem.

47 Testamento de Alonso Martínez. Córdoba, 31-8-1598. AHPC, Esc. 1, leg. 7, exp. 8, f. 208r.

48 Sucesión de Blas de Peralta. Córdoba, 1600. AHPC, Esc.1, leg. 10, exp. 1. f. 117 r.

49 Sucesión de Martín de Salvatierra. Córdoba, 1605. AHPC, Esc.1, leg. 17, exp. 12.

50 AC, 04-III-1610. Santillán Vélez, 1884, libro 5 : 128-129.

51 Concierto. Córdoba, 4-II-1620. AHPC, Reg. 1, t. 35, f. 127v. 
Estos cuadros son apenas una muestra de lo que se podía percibir del ejercicio de cada oficio o socio-ocupación. Algunas de ellas eran de tiempo completo (mayordomo), y otras habilitaban tener varios trabajos, labores o contratos simultáneos. De Juan de Arana, sacristán, sabemos que en 1600 firmó un recibo de pago por 3 pesos en concepto del servicio de entierro de un yanacona ${ }^{52}$. Algunos de estos sacristanes contaban a veces con saberes especiales, como es el caso de Andrés Paxón, que por su conocimiento de lecto-escritura, daba clases de primeras letras y llevaba los libros de entierro del cura ${ }^{53}$ si bien su subsistencia no dependía exclusivamente de estos servicios ya que contaba con ganados y un par de chacaras.

Por otro lado, los ingresos económicos de tenderos y pulperos no pueden calcularse de la misma manera porque provienen del trabajo diario de comercialización cuyo movimiento sólo es factible de analizar a través de libros de cuenta hasta el momento no identificados. Subsidiariamente los testamentos, pueden brindar algunos datos sobre sus deudores y acreedores pero no mucho más. Los pulperos se concentraban en la venta de productos alimenticios, mientras que los tenderos tenían una gama de mercaderías más amplia. Así por ejemplo sabemos que para 1600, a Jhoan Bisente, veneciano, se le había fijado un arancel de precios para los productos que tenía en su pulpería: vino de Paraguay, de Castilla y de Chile, pasas, higos, jabón, diacitrón, queso, azúcar de Brasil, tocino, conservas del Paraguay, dulce de membri110 , etc. Otro tipo de servicios que brindaban los pulperos era el de casa de empeño ${ }^{54}$.

La ausencia de libros o registros de gastos de pulpería no impide valorar la actividad como un medio de vida relativamente redituable en la medida de que para 1615 había, al menos, seis pulperías que funcionaban en la ciudad de Córdoba ${ }^{55}$. Aunque $a$ priori, podríamos considerar que se trata de una actividad baja y poco estimada socialmente, es significativo que Jhoan Bisente, pulpero residente, solicitara la vecindad en el año 1606 , y el cabildo se la concediera ${ }^{56}$. Seguramente esta concesión poco usual del cabildo se explica por la situación marginal y temprana de la ciudad de Córdoba en aquel momento. No todos los pulperos, sin embargo, lograban adquirir una encumbrada posición como Jhoan Bisente. Luis de Villamarin, por ejemplo, residente y pulpero - que no sabía firmar pero tenía una tienda en la ciudad en la que vendía vino, jabón, velas de sebo, y otros productos-al momento de su testamento, en 1618, se encontraba solo, sin hijos ni mujer, pobre, hasta el punto que solicitaba que se lo enterrara de limosna $^{57}$. Alquilaba su tienda al capitán Juan de Ludueña, a quien le debía una suma no especificada de dinero, pero que da cuenta de los lazos de dependencia que estos sujetos construían, necesariamente, con el sector alto de la sociedad. Igualmente, el general don Pablo de Guzmán, le había entregado mercaderías cuya devolución solicitaba. La falta de conocimiento de la escritura hacía que no pudiera tener claras sus cuentas y desconocía la deuda por el alquiler, confiando en "lo que dijere el capitán", o de las candelas entregadas para su venta por Elvira de Zavala, "que ella tiene quenta de la cantidad que es". De la misma manera, Domingo de Valladares le dejó dos arrobas de vino "que parte dello esta en la tienda". Ello explica, al menos en parte, la pobreza en

\footnotetext{
Sucesión de Martín de Salvatierra. Córdoba, 1605. AHPC, Esc.1, leg. 17, exp. 12, f. $251 \mathrm{r}$.

Cuenta y descargo de los bienes de Andrés Paxón. Córdoba, 1602. AHPC, Esc.1, leg. 15, exp. 1. ff. 6 y ss.

Luis de Acevedo como tutor y curador ad liten de los indios de Santiago del Estero y Esteco en la causa criminal de oficio contra los dichos por muerte dada a Gerónimo indio. Córdoba, 1609. AHPC, Esc. 1, leg. 21, exp.1.

AC, 25-VIII-1615. Santillán Vélez, 1884, libro 5: 388-390.

AC, 25-II-1606. Santillán Vélez, 1883, libro 4: 208-209.

Testamento de Luis de Villamarín. Córdoba, 7-VII-1618. AHPC, Reg. 1, f. 268r.
} 
la que lo encuentra la muerte. Al respecto, cabe señalar que si bien en el caso de Villamarín muestra un desconocimiento de la lecto-escritura, no ocurría lo mismo con todos los miembros de los segmentos medios. En efecto, de un total de 88 sujetos -de diferentes ocupaciones- cuyas escrituras analizamos 59 de ellos (68\%) supieron firmar.

En cuanto a los tenderos y mercaderes, había una gran variabilidad en cuanto su condición socioeconómica. Los tenderos tenían una residencia más estable en la ciudad; eran la mayoría de las veces rentistas que residían en el mismo inmueble donde realizaban sus tratos. Algunos de ellos se autodenominan también "tratantes" aunque bajo esta categoría también podían incluirse otros comerciantes de mayor envergadura como los que hacían tratos comerciales a larga distancia.

Un ejemplo de tratante que instaló una tienda en la ciudad es el de Francisco de Narbáez, portugués, ingresado por el puerto de Buenos Aires sin licencia, aproximadamente en 1595 y empadronado en $1607^{58}$, que declaraba tener por entonces un caudal de tres o quatro mil pesos. Narbáez había dejado su mujer e hijos en los reinos de Portugal, por esta razón su muerte dio lugar a un largo expediente. A su muerte (1614) su tienda estaba nutrida de los más variados objetos muchos de los cuales provenían de otras regiones e incluían desde alimentos (botijas de vino, barriles de confitura, diacitrón y conservas, cajetas de carne de membrillo, pimienta, arroz de Brasil, botijas de aceite y aceitunas, etc.), ropa de la tierra para los indios (sombreros, camisetas, etc.), cordobanes y telas de diversa calidad y origen (cordellate, paño, ruan, telilla, cambray, tafetán de la China, caniquí de la India, etc.), herramientas (tijeras de sastre, alfileres, etc.), hasta bienes de uso cotidiano como cera del Paraguay, candelas de cera del Brasil y jabón ${ }^{59}$. Los contadores nombrados realizaron un inventario pormenorizado y venta en almoneda para saldar las deudas contraídas y cobrar las cuentas pendientes del difunto. El resultado de este largo proceso muestra que Narbáez tenía 1.764 pesos en bienes, ninguno de los cuales estaba constituido por algún inmueble. No obstante, luego de los alcances y descargos, pago de costas y demás asuntos sólo quedó para repartir a sus herederos la suma de 239 pesos y 1 real. Este caso, y otros que podríamos acercar, muestran que muchos de estos comerciantes o tratantes trabajaban con mercaderías en consignación o realizaban transacciones a crédito, que les permitía un flujo de mercaderías muy variado y también vivir con cierta comodidad. A la hora de poner las cuentas en limpio, no era mucho el patrimonio real con el que contaban, y menos aún luego de que la justicia se cobraba las costas del proceso sucesorio.

Por su parte, los denominados mercaderes, a diferencia de los tenderos/tratantes locales eran comerciantes itinerantes que convenían pequeñas compañías con residentes en la ciudad para la venta de mercaderías en otras jurisdicciones de manera tal que se encontraban ausentes de la ciudad por períodos prolongados (véase, por ejemplo, Hernando Blanco que se concierta para llevar ropa, hierro y otras cosas a Potosí; por cada 8 arrobas recibiría 25 pesos de plata $^{60}$, o Miguel Catalán que se concierta para llevar mercaderías a Santa $\mathrm{Fe}^{61}$, o Francisco Casado residente se concierta para llevar vino embarrilado del Paraguay, cajas de confituras y diacitrón para vender en Santiago del Estero durante tres meses, por 50 pesos pagados en lienzos ${ }^{62}$ ).

\footnotetext{
58 Binayán Carmona, 1973: 229.

59 Inventario y almoneda de los bienes fincados por muerte de Francisco Narbáez. Córdoba, 1615. AHPC, Esc.1, leg. 35 , exp. 2.

60 Concierto para llevar mercaderías. Córdoba, 12-III-1591. AHPC, Reg. 1, t. 6, f. 17 v.

${ }_{61}$ Compañía para comerciar. Córdoba, 1588. AHPC, Reg. 1, t. 4, f. 60.

62 Concierto. Córdoba, 23-II-1598. AHPC, Reg.1, t. 10, f. 125r.
} 
En el interior de los segmentos medios, existían entonces marcadas diferencias, no sólo determinadas por el nivel de riqueza y el tipo de ocupación antes observados, sino por otros rasgos que no es posible desarrollar con amplitud en este trabajo, como son la antigüedad en la ciudad, los vínculos, el nivel de alfabetización, la opinión de los otros y el acceso al crédito. Todos ellos fueron condicionantes del ordenamiento jerárquico de estos sujetos.

El cabildo también constituye fuente de trabajo y progreso para numerosos miembros de los segmentos medios, en la medida de que firma contratos con algunos de ellos para realizar obras importantes. Tal el caso de Miguel de Bidaure carpintero que contrata en 1607 el arreglo de las casas del cabildo por el precio de 270 pesos corrientes a realizar en dos meses ${ }^{63}$.

\section{Libertad, vulnerabilidad y coerción social}

El sector medio puede identificarse jurídicamente a partir de ciertos derechos y obligaciones específicas, que permiten delinearlo con cierta precisión. Sus miembros no pagan tributo ni impuestos a la Corona, están al margen de las determinaciones de parentesco y linaje y por ello gozan de gran libertad de acción y decisión, lo cual configura una experiencia individual diferente a la de los otros dos segmentos. La legislación -según Recopilación de 1680 - no regula su actividad en tanto no están identificados como grupo; sólo los contempla en la medida de que participan de alguna corporación (médicos, abogados, soldados a sueldo); o bien por el cumplimiento de alguna función rentada y transitoria dentro de la administración española (intérpretes, testigos, peritos, etc.).

Posiblemente la característica más notable de los miembros de esta franja social es su libertad de residencia: pueden permanecer en la ciudad o desplazarse a otras, impulsados por la búsqueda de nuevos horizontes. Encomenderos, vecinos e indios de encomienda estaban obligados, por ley, a permanecer en el lugar en el que tenían sus feudos o sus pueblos, a riesgo de castigo (perder la encomienda o enfrentar el castigo físico). Sin embargo, la movilidad entre la ciudad y el campo y los viajes a otras gobernaciones, al Perú o a Charcas fue un rasgo común a todos, sea obligados -en el caso de los indios ${ }^{64}$-, sea por intereses comerciales o judiciales -en el caso de los encomenderos.

Esta libertad, no obstante, tiene los límites que imponen los intereses de los cabildantes que actúan condicionando y limitando la acción de esta franja social intermedia. Las decisiones fundamentales relativas a su trabajo -el precio de venta de los productos que ofrecen, el número de pulperías que tendrá la ciudad, dónde se establecerá el molino, qué fletes se autorizan, etc.- se desarrollan sin su participación y por ello, en resguardo de intereses que son de la "república" y que actúan como condicionantes de su acción.

El cabildo orienta la conducta de este segmento, en particular, su conducta mercantil y laboral. Los sujetos que formaban parte del entre-medio no estaban agremia-

63 AC, 23-IV-1607. Santillán Vélez, 1883, libro 4: 380-381.

${ }_{64}$ En general en la gobernación del Tucumán, y con mayor énfasis en Córdoba, fue común el desplazamiento involuntario de indios a otras regiones apoyando los viajes de fletes. Muchos de ellos no volvían e, incluso, hay pruebas de que eran vendidos en Charcas o en Perú. A pesar de los esfuerzos de la Corona para evitar esta situación, no hubo mayores cambios hasta que la población nativa fue diezmada. 
dos ni eran representados políticamente por nadie ante el cabildo ${ }^{65}$, ni formaban parte de corporaciones (salvo las cofradías religiosas). Esta falta de representación de parte de una corporación o gremio, les otorgaba una gran vulnerabilidad laboral pues quedaban a disposición del cabildo que, en un proceso de complejidad creciente fue regulando los oficios, los precios, los pesos y medidas ${ }^{66}$, las mercaderías que se podían sacar de la ciudad y las que no ${ }^{67}$, la calidad de lo que se vendía ${ }^{68}$, y aquello que debía ser vendido ${ }^{69}$, etc. La institución capitular otorgaba o quitaba habilitaciones ${ }^{70}$, exigía licencias y altas fianzas para poner pulperías ${ }^{71}$, cerraba pulperías ${ }^{72}$, e incluso, tomaba los productos que necesitaba de las tiendas ${ }^{73}$; obligaba a miembros de este sector a la residencia por un año en la ciudad y al uso del oficio ${ }^{74}$, o imponía impues-

65 Recién en el siglo XVIII el Marqués de Sobremonte proveyó las primeras reglamentaciones de gremios de artesanos en Córdoba. Moyano, 1986: 20.

${ }_{66}$ Por ejemplo, regulaciones sobre precios en actas del 22-II-1606, 22-XII-1612 y 4-XII-1612 y medidas del vino en actas del 4-XI-1602, 22-IV-1603 y 25-XI-1602, 14-VII-1606. Las medidas se regulan en 01-VII-1614, 03-VII-1614, 05-VII-1614, entre otras. Las medidas y precios del trigo y del maíz en AC, 04-II-1606. El 22 de febrero de 1606 se regulan precios de vino, cabrito, gallinas, queso, maíz, cebada, biscocho, cecina, tocino, que se venden fuera del ejido de la ciudad y en las estancias. En las actas de cabildo se llega a establecer en detalle el precio de los diferentes tipos de calzados, con sus tallas, o de los vestidos que hará el sastre. Santillán Vélez, 1883, libro 4: 187-189, 197-204, 235-236; 1884, libro 5: 271-273; 276-279; 1884, libro 5: 339-343.

67 En AC del 24 de octubre de 1598 el cabildo prohíbe que se saque ganado de la ciudad por la falta que hay de alimentos. Santillán Vélez, 1882, libro 3: 106-108.

68 En AC del 24 de mayo de 1600, entre otras disposiciones, el cabildo regula cómo se ha de vender el vino a fin de que pulperos y taberneros no engañen vendiendo vino de baja calidad a precio del de alta o mezclando los vinos. Santillán Vélez, 1882, libro 3: 168-171. El 19 de agosto de 1617 se establece la calidad de los sayales y se manda sacar de la venta los sayales que no sean buenos, torcida la urdimbre, blandos y de una vara de ancho. Santillán Vélez, 1884, libro 5: 266-268.

69 AC, 02-IX-1605. Santillán Vélez, 1883, libro 4: 153-154.

70 Por ejemplo, el 23 de diciembre de 1597 el cabildo otorga a Álvaro de Mercado, morador, la exclusividad para matar animales y vender carne en la ciudad, definiendo los precios que ha de cobrar y con indicaciones sobre la calidad de la carne. Pablo de Bide, por su parte, pide licencia y la obtiene del cabildo para ejercer su oficio de cirujano, presentando sus títulos y habilitaciones traducidas. AC, 30-VIII-1612. Santillán Vélez, 1884, libro 5: 268. E1 15-XI-1604 exige que las personas que curan de medicina y cirujía exhiban los títulos. Santillán Vélez, 1883, libro 4: 107-108.

71 El 10-XI-1603 el cabildo exige licencia y 1000 pesos de fianzas para poner pulpería. Santillán Vélez, 1883, libro 4: 40-43.

72 El 7-IX-1620 el cabildo decide que se reduzca el número de pulperías de la ciudad de cinco o seis que hay a cuatro y que se pasen a la plaza para mejor controlar que no se venda vino a indios. Santillán Vélez, 1884, libro 4: $140-141$.

73 Atento a que la iglesia mayor se hace de limosna y es necesario mucha clavazón para ella y los mercaderes sin tener atención a la dicha buena obra venden a excesivos precios la dicha clavazón para remedio de lo cual dijeron que se les dé una ganancia moderada y se les tome la clavazón que hubiere menester la dicha iglesia y tasaron el millar de clavos de medio tillado a doce pesos corrientes y el millar de clavos palmares dichos a dos reales y se de tiempo para que el alguacil mayor los saque de cualquier tienda que los hallare. AC, 12-VII-1603. Santillán Vélez, 1883, libro 4: 21-22.

74 Así por ejemplo el cabildo ordena el 11 de abril de 1585 que todos aquellos que trajesen mercaderías para la venta a la ciudad estarían obligados a abrir tienda tres días en esta çiudad para que el pueblo se aproveche de ella pagando lo que valiere. AC, 11-IV-1585. Luque Colombres, 1974, libro I: 540. El 14 de octubre de 1598 el gobernador, a pedido del cabildo, obliga a oficiales zapateros, carpinteros, herreros, tejeros, vidrieros, olleros, botijeros, sastres, sederos, sombrereros y otros que pasan desde el puerto de Buenos Aires hacia el Perú a residir por un año en la ciudad de Córdoba con tienda pública de sus oficios, so pena de 10 años de destierro. Seguramente el cabildo seguía en esto un doble objetivo. Por un lado, garantizar la satisfacción de las necesidades de la ciudad y sus habitantes, sea para la realización de obras públicas como de vestido, mobiliario, etc. Por otro lado, se trataba de un modo de control de los recién arribados a Indias, muchos de ellos sin licencia, obstaculizando su paso directo al Perú. 
tos no autorizados por la Audiencia ${ }^{75}$; decidía a quién se podía vender determinados productos $^{76} \mathrm{y}$ dónde ${ }^{77}$. Aquí está el centro de su acción en relación a este segmento. Estas regulaciones están estipuladas en las Ordenanzas del Virrey Toledo sobre los fieles ejecutores, que se transcriben en el acta de cabildo del 11/I/1610 y que, a partir de este momento, será citada como legitimación de las múltiples coacciones que se impusieron a las tareas de pulperos, tenderos, artesanos, barberos y otros.

Las ciudades americanas coloniales fueron para sus habitantes espacios altamente vulnerables; podían verse arrasadas por fenómenos naturales, enfermedades, epidemias, plagas, hambrunas, etc. No nos referimos a la noción de vulnerabilidad asociada al clima y a otros fenómenos naturales, aspecto que ha sido estudiado con rigor para el caso de América en una reciente compilación de Arrioja Díaz Viruell y Alberola Romá ${ }^{78}$, que afecta por igual a amplias capas de población. Estamos intentando reconocer en qué puntos este segmento bastante delimitado del cuerpo social estaba más expuesto a riesgos y amenazas de pérdida de algún bien conquistado (una pequeña empresa o taller, un pequeño patrimonio acumulado, libertad, condiciones de vida y reconocimiento social, etc.). Nos referimos a la vulnerabilidad económica que significa que estaban más sometidos a los cambios negativos de su patrimonio; a la vulnerabilidad social, que producía cambios hacia abajo en sus inscripciones de estamento de pertenencia; a la vulnerabilidad jurídica, que devenía de una justicia estamental, a la vulnerabilidad laboral. El riesgo de pérdida es lo que define propiamente a la vulnerabilidad, y a ella nos referimos ${ }^{79}$.

En efecto, los miembros de este segmento social sufren, con frecuencia, cambios más o menos abruptos en su patrimonio, pudiendo algunos de ellos experimentar un descenso a situaciones de mucha precariedad. De allí la constante que se observa de diversificación del patrimonio y del savoir faire. Por ejemplo, Martín de Fonseca era tanto barbero, espadero y productor rural ${ }^{80}$; Andrés Contreras era soldado, sastre e intérprete $^{81}$; Enrique Alberto era carpintero y tratante, entre otros ${ }^{82}$. Puede reconocerse que el mundo laboral de los segmentos medios era frágil. No era infrecuente que algunos cayeran en la cárcel pública por deudas contraídas, como en el caso de

75 Se trata de la sisa, impuesta sobre el vino e incluso sobre otras mercancías a fin de realizar obras públicas iglesia mayor, hospital, casas del cabildo y fundamentalmente la acequia- (AC, 02-III-1606, 11-XII-1609 y 11-I-1610. Santillán Vélez, 1883, libro 4: 217; 1884, libro 5: 63-69 y 105), imposición que es negada por la Audiencia-11-XII-1610-, a pesar de que se gozó de ella por casi un año y de que el Oidor Alfaro, en su estadía en la ciudad, autoriza por ocho meses, para obras públicas, a cobrar uno de cada diez cuartillos de vino (AC, 18-V-1611. Santillán Vélez, 1884, libro 5: 221). Sin embargo, las ambigüedades del cabildo respecto de ello son frecuentes y establece que se aplique sobre el vino que entrara a la ciudad, lo cual llevó a que faltara el vino porque los mercaderes que lo traían ya no querían venderlo en la ciudad. Como consecuencia de ello, cambia el sistema y se asigna sobre el vino vendido (AC, 27-IV-1612. Santillán Vélez, 1884, libro 5: 243). Otras imposiciones de sisa al vino son de las AC de 20-VI-1615, 26-VI-1615 y 20-IV-1616. Santillán Vélez, 1884, libro 5: 377-384, 430-432.

76 Los pulperos que vendan vino a los indios, ignorando la prohibición del cabildo al respecto, tendrán pena pecuniaria. AC, 30-X-1612. Santillán Vélez, 1884, Libro 5: 274.

77 Que quienes amasan pan no lo vendan en sus casas sino en la plaza pública AC, 9-XI-1617. Santillán Vélez, 1884, libro 5: 539-540._Que se vendan los productos en la ciudad y no fuera de ella. Obligan, incluso, a vender los productos al menudeo en la ciudad pues, a fin de evitar los controles de los precios y la sisa, los mercaderes suelen establecer puestos de venta afuera del ejido urbano. AC, 05-V-1610. Santillán Vélez, 1884, libro 5: 137.

78 Arrioja Díaz - Alberola Romá, 2017.

79 Castel, 1997; Alwang - Siegel - Jorgensen, 2001.

80 Tapia, 2016.

81 González Navarro, 2013.

82 Rubiolo Galíndez, 2013. 
Diego de Herrera, sedero, que debió sufrir el secuestro de sus bienes y la venta en almoneda para el pago de las deudas ${ }^{83}$.

En esta misma línea de análisis vemos que la justicia era ejercida de forma dispar según la condición social. Favorecía a los beneméritos e hijos de conquistadores que no podían ir presos por deudas. Esto difiere claramente de los sectores medios, que podían ser encarcelados por deudas y, a la vez, tenían pocas posibilidades de lograr el cobro de sus deudas contraídas con miembros de la elite. Dice la legislación que conquistadores y feudatarios, "no sean presas... por deudas civiles ni se les hagan execuciones en sus armas, cauallos, bueyes carretas aperos y casas y que se entienda y guarde con los criadores de ganado" $"$. Incluso, el cabildo de la ciudad solicita a la Real Audiencia que los hijosdalgo no sean apresados en cárcel sino en las casas del cabildo ${ }^{85}$ y pocos años antes habían reconocido la necesidad de que hubiera casas de cabildo para que... puedan estar los onbres nobles presos $^{86}$. Los miembros de la franja social que estudiamos no tienen esta posibilidad e, incluso, la cárcel puede significar la vulnerabilidad máxima. Así lo expresa el indio Diego, zapatero, oriundo de Santiago del Estero, aprehendido por la muerte del indio Gerónimo quien al ser interrogado sobre el motivo de su huida respondió "que era solo y sin amo y que si le prendiesen no tendría quien bolbyese por el ni le diese de comer"'87. La vulnerabilidad se observa también en el accionar implacable de la justicia, que suele escamotear su intervención frente a ciertas transgresiones de los grupos de los extremos pero que, en el caso de los grupos medios, son castigados. Hasta donde hemos podido indagar, en el período que nos compete se desarrollaron sólo dos juicios por amancebamiento y ambos afectaron a la franja intermedia ${ }^{88}$.

Los sujetos que en la documentación aparecen como más vulnerables y pobres son aquéllos que no pueden dar cuenta de la existencia de vínculos de algún otro tipo que no sea el económico a muy pequeña escala: el alquiler de una habitación a un vecino o, en el caso de algunos pulperos, el recibir en consignación algunos pocos productos. Es el caso, por ejemplo, de Luis de Villamarin, al cual ya nos referimos, que al momento de su testamento, en $1618^{89}$, se encuentra solo, sin hijos ni mujer, sin herederos ascendientes ni descendientes, no forma parte de cofradía alguna y es sumamente pobre, hasta el punto que solicita que se lo entierre de limosna. Muchos miembros de los segmentos medios, en su calidad de viajeros, "estantes", estaban solos y no establecieron vínculos estables, no contaban con familia, hijos o deudos en la ciudad. El caso de algunos mercaderes portugueses es un ejemplo claro de ello. Esta movilidad, se correlaciona con vínculos frágiles y con una alta vulnerabilidad.

83 Gaspar Rodríguez contra Diego de Herrera por cobro de pesos. Córdoba, 1614. AHPC, Esc.1, leg. 32 , exp. 6.

${ }_{84}$ Real Cédula dirigida a la Audiencia de Charcas y demás justicias que vean lo que esta proveydo cerca de que los conquistadores y feudatarios en las tierras que conquistaron y tienen feudos no sean presos por deudas civiles y que lo mismo guarden a los de la ciudad de Talauera de la Prouincia de Tucuman. Madrid, 13-09-1625. Archivo General de Indias [España], Buenos Aires, 5, L1/1/138 v, L1/1/138 v.

85 AC, 29-VII-1609. Santillán Vélez, 1884, libro 5: 30-39.

86 AC, 29-III-1606. Santillán Vélez, 1883, libro 4: 223-224.

87 Luis de Acevedo como tutor y curador ad liten de los indios de Santiago del Estero y Esteco en la causa criminal de oficio contra los dichos por muerte dada a Gerónimo indio. Córdoba, 1609. AHPC, Esc. 1, leg. 21, exp.1, f. $11 \mathrm{v}-12 \mathrm{r}$.

88 Proceso contra Alonso Díaz de los Álamos por amancebamiento con Isabel Rosales. Córdoba, 1607. AHPC, Esc. 1, leg. 17, exp. 2 y Proceso contra Juan Barba Verdugo por amancebamiento. Córdoba, 1628. AHPC, Esc. 1, leg. 60, exp. 12 .

89 Testamento de Luis de Villamarín. Córdoba 7-VII-1618. AHPC, Reg. 1, t. 32, f. 268r. 
En general, los individuos que han quedado representados en las fuentes analizadas se caracterizan por su capacidad de afrontamiento y resistencia a esta vulnerabilidad potencial, de modo que los efectos de un peligro virtual pueden ser, si no previstos, sí resistidos mediante estrategias que dan cuenta que poseían recursos para hacer frente al riesgo de pérdida. Estos soportes son varios y entre ellos destacamos su participación en redes de sociabilidad (estrategias informales) y demanda articulada (estrategia formal).

En relación al primer soporte, los sujetos mejor integrados y menos expuestos a cambios bruscos de capital o condición social son aquellos que mejores vínculos han desarrollado. Ello ocurre por ejemplo, con Sebastián Casero, poblero de la encomienda de Soto a quien se le reconoce al momento de su muerte haber tenido vínculos económicos con personas de muy diferente origen y nivel social ${ }^{90}$. Puede citarse también el caso de Jhoan Nieto, mestizo, escribano público y de cabildo que a fines del siglo XVI, logró vincularse estrechamente a la élite a través del cargo de escribano y se integró de tal forma que logró un muy buen pasar con tierra e indios ${ }^{91}$.

Simon Duarte, viudo, portugués, prestamista y pulpero, que en 1603 se desempeñaba como poblero, integrado a la sociedad cordobesa, al momento de su testamento llevaba, al menos, 15 años viviendo en la ciudad. A lo largo de su vida tuvo un crecimiento económico relativo pues su capital económico, seguramente con altas y bajas, varió en estos 15 años de 100 pesos a 450 aproximadamente. Puede alegar vínculos de naturaleza económica, como prestador de miembros de la élite, y de naturaleza económica y afectiva, con otros portugueses de la ciudad. Deja a dos comerciantes portugueses, moradores, como albaceas, curadores y tutores de su hijo. Al momento de establecer lazos seguros de confianza se orienta hacia miembros de su misma nacionalidad. Especialmente entre portugueses, los lazos de amistad fueron de primer orden para no caer preso por deudas o no perder todo en una sola maniobra.

Son comunes los conciertos de indios urbanos, libres, o indios encomendados con artesanos con el objeto de que éstos les enseñaran la profesión. La documentación de archivo, profusa en estos conciertos, muestra de qué manera estas relaciones aprendiz-artesanos podían proteger y apoyar la integración de estos aprendices e, incluso, muchas de ellas terminan constituyendo la base de relaciones parentales, en particular, cuando el aprendiz contrae matrimonio con una hija del artesano.

Las relaciones que los miembros de esta franja intermedia puedan tener con miembros de la elite política cabildante o con gobernadores fueron fundamentales para el ascenso social y la integración a la ciudad, para conseguir buenos contratos de trabajo y para evitar problemas con la justicia. El platero Juan López Reina, vecino, con 16 años de residencia en la gobernación, fue acusado por el encomendero Gerónimo de Bustamante de fundir moneda de plata (tostones de plata de a ocho reales el peso) con el objeto de realizar tazas, jarros, cubiletes y otros objetos. Este mismo encomendero presenta, como testigos, a otros miembros selectos del reducido grupo de vecinos de la ciudad. Lo interesante es que, todos ellos testifican en favor del platero y declaran desconocer esta situación. La justicia falla en favor del platero y G. de Bustamante pide apelación ante la Real Audiencia, que le fue otorgada. Desconocemos qué llevó a G. de Bustamante a hacer esta denuncia y por qué estaba tan ensañado en que la justicia actuara contra el platero, pidiendo incluso,

\footnotetext{
Sucesión de Sebastián Casero. Córdoba, 1643. AHPC, Esc.1, leg. 80, exp. 2. González Navarro, $2012: 14$. González Navarro, 2018: 43.
} 
pena de muerte, pero de este juicio nos interesa destacar que, según expresan todos los testigos, al menos seis beneméritos (Bernabé Mexía, Juan de Ludueña, Baltasar Gallegos, Pedro de Soria el joven, Miguel de Moxica) en el término de menos de un mes visitaron al platero en su casa, lo que da cuenta de sus vínculos y esta amistad le valió como reaseguro frente a tamaña acusación.

En relación al segundo soporte, formal, se trata de algunos casos relevados en los que los miembros de esta franja social pudieron organizarse grupalmente y defender algún derecho regateado por la institución capitular. Especialmente interesante resulta el acta de cabildo del 24 de mayo de 1600 en la que establecían una serie de controles a las pulperías: se incorporaba una disposición del fiel ejecutor que penaba a cuatro pulperos por no tener peso ni vara, y se incluyeron disposiciones como que pulperos y taberneros no tuvieran más de un barril de vino abierto y que avisaran al fiel ejecutor cuando abrieran el siguiente, dado que solían tener dos o más tipos de vino y vendían el de menor precio como si fuera el de mayor, o mezclaban ambos. Otra disposición establecía que mercaderes y tratantes tuvieran muestras de los paños y rasos que vendían a fin de evitar el engaño a quienes los compraban ${ }^{92}$. En la próxima sesión del cabildo se trató una petición firmada por seis pulperos en la que apelaban este auto y sus disposiciones, alegando que no contaban con varas y peso propio y que por ello usaban las que les prestaban dos de ellos y "que no pesamos ni vareamos cosa alguna sino con peso y balanza fiel y varas selladas con el sello de la ciudad". Pidieron también anulación de la ordenanza sobre paños y del auto que decía que quien entrara vino en la ciudad y lo comenzara a vender ya no podía sacarlo, lo cual era en "grandísimo agravio" a los mercaderes que pasaban y vendían vino a los pulperos. Lo interesante de este caso es que, por un lado, los pulperos actuaron conjuntamente lo cual es prueba de algún tipo de organización entre ellos para la defensa de sus derechos. Pero además, interesa destacar que el cabildo suspendió la ordenanza de los paños, moderó las condenaciones por la falta de medidas y pesos y confirmó la necesidad de que los pulperos tuvieran barril sellado del vino para la venta. Esto es, el reclamo tuvo algún efecto positivo. No se trata de un hecho aislado. Así en un acta del 14 de julio de 1606 se expresa que los pulperos se quejaron porque se les cobraba la sisa del vino antes de que hubieran vendido el producto y solicitaron al cabildo que se les diera un mes para dicho pago. Algo semejante ocurrió el 17 de diciembre de 1612 cuando oficiales sastres y zapateros, conjuntamente, pidieron revocación de la tasa y aranceles que había dispuesto el cabildo en la sesión anterior, del 4 de diciembre, en la que estipularon los precios con minuciosidad excesiva ${ }^{93}$. En el mismo sentido, y pidiendo la revocación de la nueva vara de medir, se manifestaron los mercaderes Pedro Torino y Manuel López, aunque sin éxito ${ }^{94}$. Es posible que otros reclamos conjuntos no consten en actas.

En las trayectorias de vida que conocemos, se observa que en general el éxito de cada individuo dependía de su capacidad para actuar de manera inteligente, rápida y movilizar vínculos relevantes. Esto es lo que hace la diferencia para los sujetos de esta franja intermedia y que define su ubicación en relación a las instituciones coloniales: su capacidad para movilizar lazos, para actuar con premura, con atención a cada nueva situación. Es interesante para ejemplificar este hecho

\footnotetext{
AC, 24-V-1600. Santillán Vélez, 1882, libro3: 168-169.

AC, 04-XII-1612. Santillán Vélez, 1884, libro 5: 276-277.

AC, 18-VII-1614. Santillán Vélez, 1884, libro 5: 344-345.
} 
el caso de Ignacio Domínguez, tendero portugués, que ante el fallecimiento del rico comerciante Juan de Soria presentó inmediatamente demanda para conseguir que la justicia reconociera la deuda de \$258 que tenía con él por ciertas prendas de Castilla que había tomado de su tienda. Logró que la justicia reconociera la deuda, que se enviaran parte de los bienes del finado a remate y que se le pagara. Otros deudores, que presentaron posteriormente sus pruebas, ricos mercaderes, tuvieron que esperar años para que sus deudas fueran pagadas. Para dar solamente una idea del capital que movían estos grandes comerciantes de origen portugués a diferencia de aquéllos pertenecientes a los segmentos medios, vemos que Juan de Soria, en una sola transacción, recibió 2700 pesos en oro que vendió en 10.000 pesos de plata corriente, y cuyo acreedor, también portugués, el capitán Lope de la Peña, reclamó, alegando, incluso, que como la deuda era anterior a la de Ignacio Domínguez, debió haber sido cobrada antes ${ }^{95}$.

\section{Consideraciones finales}

Hemos realizado sólo algunas consideraciones iniciales sobre la constitución de esta franja media en la gobernación del Tucumán. Queda aún mucho por indagar, sin embargo, consideramos indispensable para la comprensión y el análisis de la sociedad colonial temprana, dar cuenta de la presencia y relevancia capital que estos segmentos medios tuvieron para el sostenimiento y consolidación de las primeras ciudades hispanoamericanas. Los estudios centrados en las élites coloniales o bien, en los sectores subalternos (en especial indios y esclavos de origen africano) han soslayado u opacado la relevancia de este segmento.

En el presente trabajo, no nos hemos referido a algunos aspectos que consideramos relevantes para arribar a algunas conclusiones más específicas sobre comportamientos, experiencias y mentalidades de este segmento social. Así, falta aún el desarrollo de las identidades experimentadas y asignadas; de los criterios de jerarquización de sus miembros; de sus relaciones vinculares y clientelares; de sus lazos parentales; del afán de lucro que los movió y de su tensión con ciertas cualidades valoradas, como la piedad cristiana; de los procesos de mimetización con relación a los sectores altos y de diferenciación en relación a los sectores subalternos; los incipientes procesos de división del trabajo, conflictos, violencias, etc. Es más, cabe advertir que las observaciones realizadas atañen exclusivamente a miembros varones de la franja intermedia en el período y región delimitados. La situación de las mujeres de este segmento social fue significativamente.

Las observaciones realizadas, aunque fragmentarias, nos permiten sin embargo, realizar algunas consideraciones generales sobre los sujetos estudiados. En principio, esta franja intermedia no constituía un grupo social con alguna unidad de fines, intereses o estrategias. La conducta, mentalidad, educación, ideales de promoción social, cultural y económica de los miembros de esta franja exhiben mucho menos homogeneidad que los de la élite o los ricos comerciantes, profusamente estudiados por la historiografía colonial.

95 Germán Martín contra don Juan de Soria sobre cumplimiento de un contrato. Córdoba, 1593. AHPC, Esc. 1, leg. 9, exp. 2 . 
Se trató de un segmento poblacional heterogéneo, integrado por numerosos y jerárquicos estamentos ocupacionales, cuya unidad radica principalmente en el hecho de que sus miembros poseían como atributo principal un saber útil -o varios-, un savoir faire no necesariamente profesional que administraban conforme a sus necesidades de subsistencia e integración social. Si bien es difícil establecer conclusiones relevantes sobre los procesos de identificación de estos sujetos, puede afirmarse que no hay una identidad que los involucre como colectivo social ni posiblemente consciencia de pertenencia a algo así como un "grupo". Pareciera que más bien se trata de identidades delineadas desde el punto de vista exogrupal y que afectan a la socioprofesión. Las diferentes categorías funcionales no fueron productoras de identidades compartidas, se trató de agrupaciones -no de grupos cohesivos- que en situaciones de fricción o de conflicto, en particular con el cabildo, pudieron organizar reclamos conjuntos, pero no más que ello. Estos son los únicos casos de conflictos colectivos resueltos de manera colectiva. Todas las otras situaciones conflictivas identificadas son individuales (juicios por deudas y otros) y afectan a sujetos particulares. Hasta ahora no hemos reconocido otros factores cohesivos que den cuenta de algún proceso de constitución productiva de grupos al interior de esta franja intermedia. El proceso, hipotetizamos, será el de una cada vez mayor definición y delimitación de prácticas, identidades y comportamientos relativos a cada una de las ocupaciones, con su correlato de mayor rigidez y especialización, proceso que absorberá todo el siglo XVII. Concomitantemente, la conformación multiétnica de esta franja social en los primeros años de asentamiento español creemos que se va difuminando en beneficio de una mayor rigidez según la cual, comienzan a cerrarse las posibilidades de indios y mestizos para la práctica de ciertas ocupaciones artesanales en calidad de oficiales. Cada vez más el ingreso a estas ocupaciones va a ser celosamente custodiado hasta que en el siglo XVIII, con las ordenanzas gremiales, la industria artesanal prohíba el acceso a indios y negros que ocuparán exclusivamente el lugar de obreros y no ya de oficiales artesanos. La carencia de mano de obra del primer medio siglo de presencia española en la región llevó, en esta primera etapa, a la admisión como oficiales a indios, mestizos y portugueses cristianos nuevos, situación que no pudo revertirse, a pesar de los esfuerzos del cabildo, que no pudo exigir cartas de habilitación ni imponer el complejo tejido regulador que intentó.

Fueron sujetos vulnerables que no contaron con colegios profesionales, gremios, instituciones, funcionarios o amos que pudiera mitigar las situaciones dañosas que puedan afectarlos (crisis económica, desocupación, cárcel, deudas, etc.) y, en todo caso su éxito dependió de las redes personales que pudieron construir para amortiguar dichas situaciones y de su capacidad para organizar demandas conjuntas. $\mathrm{Su}$ alta movilidad espacial se relaciona con vínculos frágiles.

Hemos reconocido a pequeños comerciantes locales, pulperos, tenderos, tratantes, con diferentes fortunas, pero en todos los casos inferiores a los dos mil pesos, que comerciaron con bienes que circulaban en la economía regional. También hemos podido conocer a algunos artesanos, por lo general humildes, dedicados a su profesión pero también a otras actividades que se pudieran ofrecer, y medianamente especializados en sus tareas. En este conjunto sólo aparece como diferencial el caso de los plateros, especializados, por lo general con un capital reconocido, y con vínculos estrechos con cabildantes, encomenderos y ricos comerciantes. Muy pocos artesanos trabajaron con habilitaciones que garantizaran el nivel de su trabajo. Lo mismo 
sucedía con médicos, cirujanos y barberos, no siempre especializados, que podían cumplir también otras funciones.

La jerarquización, seguramente era notoria y estaba basada en múltiples indicadores. La antigüedad en la ciudad, los vínculos, las ocupaciones, la alfabetización, la opinión de los otros, la calidad, el estilo de vida, el acceso al crédito y la etnia fueron determinantes en el ordenamiento jerárquico de estos sujetos, que vivieron sus vidas en un entorno en el cual cada uno ocupaba un lugar social en base a todos estos criterios. No todos los artesanos o pulperos tuvieron el mismo nivel de reconocimiento social o de riqueza ni los mismos vínculos, y no todos tuvieron la posibilidad de imitar prácticas y modales de la elite. Cuanto más exitosas fueron estas estrategias de mimetización, mayores posibilidades tuvieron de ocupar una posición de reconocimiento.

\section{Referencias bibliográficas}

Alwang, Jeffrey S. - Siegel, Paul B. - Jorgensen, Steen. Vulnerability: a View from different Disciplines. Social Protection. Discussion papper Series, World Bank, 2001.

Arrioja Díaz Viruell, Luis Alberto - Alberona Romá, Armando (eds.). Clima, desastre y convulsiones sociales en España e Hispanoamérica, siglos XVII-XX. México: El Colegio de Michoacán, Universidad de Alicante. 2017.

Assadourian, Carlos Sempat. "El tráfico de esclavos en Córdoba (1588-1610), según las actas de protocolos del Archivo Histórico de Córdoba". En Cuadernos de Historia. Córdoba: Universidad Nacional de Córdoba, Instituto de Estudios Americanistas, n XXXII, 1965.

— "Potosí y el crecimiento económico de Córdoba en los siglos XVI y XVII". En Volumen Homenaje al Dr C. Garzón Maceda, coordinado por Carlos Luque Colombres. Córdoba: Dirección General de Publicaciones. U.N.C., 1973, 169-185.

Berberián, Eduardo. Crónicas del Tucumán Siglo XVI. Córdoba: Comechingonia, 1987.

Binayan Carmona, Narciso. "El padrón de extranjeros del Tucumán de 1607”. Investigaciones y Ensayos, ${ }^{\circ} 15$ (1973), 207-239.

Bixio, Beatriz - González Navarro, Constanza. “Introducción”. En Mestizaje y configuración social (Córdoba siglos XVI y XVII), dirigido por Bixio, Beatriz - González Navarro, Constanza. Córdoba: Brujas, 2013, 7-18.

Castel, Robert. La metamorfosis de la cuestión social. España: Paidós, 1997.

Deforge, Yves. "La transmission et la préservation des savoir-faire et les enseignements techniques". En Savoir faire et pouvoir transmettre: Transmission et apprentissage des savoir-faire et des techniques, editado por Chevallier, Denis. Paris: Éditions de la Maison des sciences de l'homme, 1996. DOI: 10.4000/books.editionsmsh.3853.

Doucet, Gastón "En torno a la población aborigen y a las encomiendas de indios del antiguo Tucumán. Acotaciones a un libro laureado". Revista de Indias, vol. XLVII, n 179 (1987), 253-313.

González Navarro, Constanza. "La Estancia: su génesis y su estructura en Córdoba. (Gobernación del Tucumán-Virreinato del Perú-1573-1700)" En Secuencia, Publicación Cuatrimestral del Instituto Dr. Mora, México, no 74, 2009, 15-51. Disponible en http://secuencia.mora.edu.mx/index.php/Secuencia/article/view/1075/949

— "Pobleros, mayordomos y administradores en el mundo rural cordobés (1580-1650)". Surandino Monográfico, segunda sección del Prohal Monográfico, vol. II, nº 2, 2012. Disponible en http://www.filo.uba.ar/contenidos/investigacion/institutos/ravignani/prohal/mono.html 
— “Andrés de Contreras, soldado, mayordomo y sastre. Una aproximación al entre-medio de la naciente sociedad colonial. Córdoba. (siglos XVI-XVII)". En Mestizaje y configuración social (Córdoba siglos XVI y XVII), dirigido por Bixio, Beatriz - González Navarro Constanza. Córdoba: Brujas, 2013, 219-239.

— "La huella indígena en los procesos judiciales coloniales de Córdoba, 1573-1620". Memoria americana. Cuadernos de etnohistoria, vol. 26, $\mathrm{n}^{\circ} 1$ (2018), 34-56.

González Navarro, Constanza - Marschoff, María. "Materialidad y usos sociales en las "casas principales" de la ciudad de Córdoba (Siglo XVII)". Ponencia en XXXVI Encuentro de Geohistoria Regional, organizado por el Instituto de Investigaciones Geohistóricas (CONICET/UNNE), Resistencia, Chaco, 2016.

Grana, Romina. "Por ser yo hombre de buen proseder y buen trato y bibir y reputacion'. Construcción discursiva de la imagen personal en fuentes coloniales". En Mestizaje y configuración social. Córdoba. Siglos XVI y XVII, dirigido por Bixio Beatriz - González Navarro Constanza. Córdoba: Brujas, 2013, 165-192.

Guerra, Francois-Xavier. "El análisis de los grupos sociales: balance historiográfico y debate crítico". Anuario del IEHS, n 15 (2000), 117-122.

Langue, Fréderic, "Las élites en América española, actitudes y mentalidades". Boletín Americanista, $\mathrm{n}^{\circ}$ 42-43 (1992), 123-139.

Lobos, Héctor R. - Gould, Eduardo G. S. El trasiego humano del viejo al nuevo mundo. Buenos Aires: Academia Nacional de la Historia, 1998.

Lockhart, James. "Organización y cambio social en la América Latina colonial". En América Latina en la época colonial, vol 2: Economía y Sociedad, Sánchez Albornoz, Nicolás - Lockhart, James - Bowser, Frederick - Gibson, Charles - Bakewell, Peter - Florescano, Enrique - Mörner, Magnus - Mac Leod, Murdo - Morse Richard. Barcelona: Crítica, 2002, 33-78.

Luque Colombres, Carlos. Actas Capitulares, libro I. Córdoba: Archivo Municipal de Córdoba, 1974.

Mallo, Silvia. "Introducción”. En La sociedad colonial en los confines del imperio. Diversidad e identidad (siglos XVI-XIX), editado por Mallo, Silvia. Argentina: CEH Prof. Carlos A. Segreti, CHAA de la UN La Plata, 2010, 9-15.

Moyano, Hugo. La organización de los gremios en Córdoba. Sociedad artesanal y producción artesanal. 1810-1820. Córdoba: CEH Prof. Carlos A. Segreti, 1986.

Parra Garzón, Gabriela. "Cabildo y sociedad: los actores sociales de la Córdoba colonial en el discurso de la elite dirigente (1573-1630)". En La sociedad colonial en los confines del imperio. Diversidad e identidad (siglos XVI-XIX), compilado por Silvia Mallo. CórdobaLa Plata: CEH Carlos S.A. Segreti, Centro de Historia Argentina y Americana de la Universidad Nacional de La Plata, 2010.

Piana de Cuestas, Josefina. Los indígenas de Córdoba bajo el régimen colonial. 1570-1620. Argentina: Universidad Nacional de Córdoba, 1992.

Ponce Leiva, Pilar. "Versatilidad social y poderes múltiples en la América Colonial". Nuevo Mundo, Mundos Nuevos, $\mathrm{n}^{\circ}$ 7, 2007. DOI: 10.4000/nuevomundo.3231.

Rubiolo Galíndez, Marcos. "De todo un poco. La relativa prosperidad de una familia de carpinteros en Córdoba del Tucumán (ca 1600-1641)”. En Mestizaje y configuración social. Córdoba. Siglos XVI y XVII, dirigido por Bixio Beatriz - González Navarro Constanza. Córdoba: Brujas, 2013, 193-218.

Santillán Vélez, José. Archivo Municipal de Córdoba, Libros 2, 3 (1882), 4 (1883), 5, 6, 7 y 8 (1884). Córdoba: La Carcajada.

Segreti, Carlos S.A. Córdoba, ciudad y provincia (siglos XVI y XVII) según relatos de viajeros y otros testimonios. Córdoba: CEH, 1999. 
Serrera, Ramón María. La América de los Habsburgo (1517-1700), Sevilla: Universidad de Sevilla, 2011.

Tapia, Justo. "Cirujanos y barberos en la ciudad de Córdoba (1573-1640). Procesos de integración social y representaciones", En Actas del XXXVI Encuentro de Geohistoria Regional, compilado por Giordano, Mariana et alli, Resistencia, Chaco: Instituto de Investigaciones Geohistóricas, 2016, 193-202. Disponible en http://repositorio.unne.edu. ar/handle/123456789/927

Undurraga, Verónica. Los rostros del honor. Normas culturales y estrategias de promoción social en Chile colonial, siglo XVIII. Santiago de Chile: Dibam, 2012.

Von Mentz, Brígida. (coord.). Movilidad social de sectores medios en México. Una retrospectiva histórica (siglos XVII al XX). México: Centro de Investigaciones y Estudios Superiores en Antropología social, 2003. 